repeat audit conducted after a 12 -month lapse revealed overall scores ranging from 89 to $100 \%$, median $98 \%$, mean $97 \%$.

Conclusions This study shows that it is possible to substantially improve standards of clinical record-keeping in a GUM clinic staffed by clinicians from a variety of backgrounds, through the intensive application of a wide-ranging audit tool and the use of individual feedback. The repeat audit conducted a year after the 12-month intensive phase shows that these improvements appear to be both sustainable and durable.

\section{P5-S6.30 HPV CATCH-UP VACCINATION AMONG A COMMUNITY SAMPLE OF YOUNG ADULT WOMEN}

doi:10.1136/sextrans-2011-050108.586

L Manhart, A Burgess-Hull, C Fleming, J Bailey, K Haggerty, R Catalano. University of Washington (Seattle, USA)

Background Despite the high efficacy of the human papillomavirus (HPV) vaccine, uptake has been slow and little data on psychosocial barriers to catch-up vaccination exist.

Methods A community sample of 428 women enrolled in a longitudinal study of social development were interviewed about HPV vaccine status, attitudes, and barriers to HPV vaccination in spring 2008 or 2009 at $\sim$ age 22 .

Results $19 \%$ of women had initiated vaccination, $10 \%$ had completed the series, and $\sim 40 \%$ of unvaccinated women intended to get vaccinated. Peer approval was associated with vaccine initiation (Adjusted Prevalence Ratio (APR) 2.5; 95\% CI 1.7 to 3.8) and intention to vaccinate (APR 1.5; 1.2-1.9). Belief the vaccine is $<75 \%$ effective was associated with less initiation (APR 0.6; $0.4-0.9$ ) or intention to vaccinate (APR 0.5; 0.4-0.7). Vaccine initiation was also less likely among cigarette smokers and illegal drug users, whereas intention to vaccinate was more common among women currently attending school or with $>5$ lifetime sex partners, but less common among women perceiving low susceptibility to HPV (APR 0.6; 0.4-0.8) see Abstract P5-S6.30 table 4.

Conclusions HPV catch-up vaccination uptake was low in this community sample. Increasing awareness of susceptibility to HPV and the high vaccine efficacy, along with peer interventions to increase acceptability, may be most effective.

Abstract P5-S6.30 Table 4 Multivariable analyses of characteristics independently associated with vaccine initiation and intention to vaccinate among 428 young women who participated in the Raising Healthy Children (RHC) young adult survey during 2008 and 2009

\begin{tabular}{|c|c|c|c|c|}
\hline & \multicolumn{2}{|l|}{ Vaccine initiation } & \multicolumn{2}{|c|}{ Intention to vaccinate } \\
\hline & APR $(95 \% \mathrm{CI})^{*}$ & $\bar{p}$ Value & APR $(95 \% \mathrm{CI})^{*}$ & p Value \\
\hline Daily smoker & $0.5(0.30$ to 0.90$)$ & 0.02 & - & - \\
\hline Illegal drug use $†$ & $0.3(0.07$ to 0.99$)$ & 0.05 & - & - \\
\hline $\begin{array}{l}\text { Pelvic exam in the } \\
\text { past year }\end{array}$ & $2.3(1.30$ to 4.15$)$ & 0.005 & & \\
\hline $\begin{array}{l}\text { Belief vaccine is }<75 \% \\
\text { effective }\end{array}$ & $0.6(0.39$ to 0.95$)$ & 0.03 & 0.5 (0.39 to 0.71$)$ & $<0.001$ \\
\hline $\begin{array}{l}\text { Peers strongly } \\
\text { approve of vaccine }\end{array}$ & $2.1(1.42$ to 3.20$)$ & $<0.001$ & $1.5(1.15$ to 1.91$)$ & 0.002 \\
\hline Currently attending school & - & - & $1.3(1.03$ to 1.70$)$ & 0.03 \\
\hline$>5$ sex partners & - & - & $1.3(1.02$ to 1.71$)$ & 0.04 \\
\hline $\begin{array}{l}\text { Low perceived } \\
\text { susceptibility to HPV }\end{array}$ & - & - & $0.6(0.43$ to 0.80$)$ & 0.001 \\
\hline
\end{tabular}

${ }^{*} \mathrm{APR}(95 \% \mathrm{Cl})=$ adjusted prevalence ratio and $95 \% \mathrm{Cl}$ from Poisson regression with robust standard errors; adjusted for all characteristics listed in table. Further adjustment for the following characteristics made no appreciable difference in the estimates and were not included: race, education (self or parent), marital status, income, sexually active in the past 3 months, lifetime number of sex partners, condom use, history of HPV-related conditions, history of STD, religious preferences, physical health, mental health, binge drinking, and severity of or susceptibility to HPV infection.

†Excluding marijuana use.

\section{P5-S6.31 SEXUAL HEALTHCARE AMONG FEMALE SEX WORKERS WORKING OUTSIDE OF THE MAIN ENTERTAINMENT DISTRICT IN TIJUANA, MEXICO}

doi:10.1136/sextrans-2011-050108.587

${ }^{1} \mathrm{M}$ Rusch, ${ }^{2} \mathrm{M}$ Gallardo, ${ }^{2} \mathrm{R}$ Lozada, ${ }^{3} \mathrm{R}$ Lindsay, ${ }^{1} \mathrm{~V} \mathrm{~J}$ Mercer, ${ }^{1} \mathrm{M}$ L Zuniga, ${ }^{1} \mathrm{~T}$ L Patterson, ${ }^{1} \mathrm{~S}$ A Strathdee. ${ }^{1}$ UCSD, La Jolla, USA; ${ }^{2}$ PrevenCasa A.C., Mexico; ${ }^{3}$ SDSU-UCSD, USA

Background Sex work is quasi-legal in Tijuana, with a zone of tolerance (Zona Roja, or Red Light district), and a registration card system whereby female sex workers (FSW) pay an annual cost to cover HIV and STI testing. As healthcare efforts are concentrated in the Zona Roja, we set out to assess the frequency of Pap testing among FSW working outside this zone.

Methods Proyecto Amantes de la Salud (Lovers of Health Project) conducted baseline surveys among 403 FSW working in bars outside of Tijuana's Zona Roja using time-location sampling. Surveys included demographics, sexual and substance use behaviour, sex work characteristics and sexual healthcare practices. Average number of annual Pap tests over the past 5 years was calculated using left censoring for the denominator based on: (1) years sexually active and (2) years in sex trade. Descriptive statistics and logistic regression were used to assess factors associated with Pap testing in the past year

Results Participants ranged in age from 18 to 55 (Median: 28; IOR: 23-32); all were born in Mexico and 98\% reported being registered as an FSW. Sex partners included regular, non-client $(25 \%)$, regular clients (79\%) and non-regular clients (99\%). Overall, 85\% of women reported a pap test in the past year; however, only $35 \%$ of sexually active women and $52 \%$ of FSW had an average of at least one Pap test per year over the past 5 years see Abstract P5-S6.31 table 1. A

Abstract P5-S6.31 Table 1 Factors associated with reporting a Pap test in the past year among FSW in Tijuana, Mexico

\begin{tabular}{|c|c|c|c|}
\hline & $\begin{array}{l}\text { Pap test } \\
\text { past year, } \\
\mathrm{N}=344(85 \%)\end{array}$ & $\begin{array}{l}\text { No Pap } \\
\text { past year, } \\
N=59(15 \%)\end{array}$ & $\begin{array}{l}\text { AOR } \\
(95 \% \mathrm{Cl})\end{array}$ \\
\hline Age $<25$ & $99(29 \%)$ & $25(42 \%)$ & $0.44(0.18$ to 1.10$)$ \\
\hline \multicolumn{4}{|l|}{ Work colonia } \\
\hline Region A & $162(47 \%)$ & $22(37 \%)$ & - \\
\hline Region $B$ & $182(53 \%)$ & $37(63 \%)$ & - \\
\hline Lived in TJ whole life & $107(31 \%)$ & $20(34 \%)$ & - \\
\hline \multicolumn{4}{|l|}{ Education } \\
\hline$\geq 6 \mathrm{yrs}$ & $178(52 \%)$ & $28(48 \%)$ & - \\
\hline Any child & $235(68 \%)$ & $30(51 \%)$ & $2.08(0.94$ to 4.58$)$ \\
\hline Income $>3500 \mathrm{pesos} / \mathrm{mos}$ & $231(67 \%)$ & $54(92 \%)$ & $0.32(0.11$ to 0.97$)$ \\
\hline Years of SW & $6(3,9)$ & $6(3,10)$ & $0.89(0.83$ to 0.97$)$ \\
\hline Regular partner & $87(25 \%)$ & $13(22 \%)$ & - \\
\hline Casual partner (any) & $134(39 \%)$ & $19(32 \%)$ & - \\
\hline Regular clients (any) & $263(76 \%)$ & $55(93 \%)$ & $0.29(0.10$ to 0.84$)$ \\
\hline $10+$ non-regular clients & $239(69 \%)$ & $47(80 \%)$ & - \\
\hline $\begin{array}{l}\text { Condom use }<1 / 2 \text { time* } \\
\text { (regular clients) }\end{array}$ & $92(35 \%)$ & $9(16 \%)$ & - \\
\hline $\begin{array}{l}\text { Condom use }<1 / 2 \text { time } \\
\text { (non-regular clients) }\end{array}$ & $77(22 \%)$ & $3(5 \%)$ & 3.56 (0.90 to 14.09$)$ \\
\hline US clients & $133(39 \%)$ & $17(29 \%)$ & - \\
\hline Alcohol daily & $117(34 \%)$ & $11(19 \%)$ & - \\
\hline Any drug use & $42(12 \%)$ & $7(12 \%)$ & - \\
\hline Drug use $\mathrm{w} /$ clients & $35(10 \%)$ & $5(8 \%)$ & - \\
\hline STI past (6 mos) & $8(2.3)$ & $0(0 \%)$ & - \\
\hline Symptoms past (6 mos) & $45(13 \%)$ & $9(15 \%)$ & - \\
\hline $\begin{array}{l}\text { Used Antibiotics for } \\
\text { STI w/out prescription (ever) }\end{array}$ & $43(13 \%)$ & $3(5 \%)$ & - \\
\hline
\end{tabular}


small proportion (4\%) indicated they had never had a Pap test. In multivariate models, having a Pap test in the past year was negatively associated with income $>3500$ pesos/month, more years in the sex trade and having regular clients. Marginal positive associations remained with older age, reporting condom use less than half the time with non-regular clients and having any children.

Discussion Prevalence of pap tests in the past year was higher than expected and may be attributed to recent efforts by the Tijuana Municipal Health Services to increase outreach to FSWs in these areas. However, since initiating sex work, only half reported the recommended yearly Pap testing which is concerning given the increased risk for HPV infection and cervical cancer among FSW. Sexual health education, including where access services, is needed to encourage regular cancer screening among this high risk population, especially among younger women and women who have been working in the sex trade for longer durations.

\section{P5-S6.32 USING A CONTINGENT VALUATION METHOD TO UNDERSTAND CONSUMER PREFERENCES FOR CARE OF ADOLESCENTS WITH PELVIC INFLAMMATORY DISEASE (PID)}

doi:10.1136/sextrans-2011-050108.588

${ }^{1} \mathrm{M}$ Trent, ${ }^{2} \mathrm{O}$ Oian, ${ }^{3} \mathrm{~K}$ Frick, ${ }^{3} \mathrm{C}$ Thompson, ${ }^{4} \mathrm{~A}$ Butz, ${ }^{4} \mathrm{~J}$ Ellen, ${ }^{4} \mathrm{H}$ Lehmann. ${ }^{1} \mathrm{~J}$ ohns Hopkins University School of Medicine, Baltimore, USA; ${ }^{2}$ University of Maryland, Towson, USA; ${ }^{3}$ Johns Hopkins Bloomberg School of Public Health, Baltimore, USA; ${ }^{4}$ Johns Hopkins School of Medicine, Baltimore, USA

Objective Adolescent girls diagnosed with PID are at higher risk for subsequent sexually transmitted infection (STI), pregnancy, and long-term pelvic pain. Although the 72 -h post-PID evaluation provides an opportunity for risk reduction counselling, few adolescents adhere. Use of public health nurses (PHN) for clinical followup may meet the needs of this vulnerable population. The objective of this study is to estimate consumers' willingness-to-pay (WTP) for follow-up PID services by physicians and PHNs, differences by consumer type, and the differences in health-provider predicted consumer WTP values and actual consumer WTP values.

Methods A contingent valuation method was used to collect WTP data regarding co-payments to physicians or nurses for clinical service delivery from the consumers of adolescent PID services (parents $(n=121)$ and adolescents $(n=134))$ and a national sample of health providers $(n=102)$. Consumers were recruited from an academic paediatric practice and school-based health clinics in a large urban community with high STI prevalence. Participants completed a web-based survey with data uploaded to a secure server after obtaining online consent. Data were analysed using linear regression analyses.

Results The mean WTP for physician services was \$16 (SD \$16.9) for clinicians, $\$ 81.9$ (\$34.0) for parents, and $\$ 72$ (SD \$39.1) for adolescents. The mean WTP for PHN services was \$13.6 (SD \$17.4) for physicians, \$62.4 (SD \$44.1) for parents, and \$49.7 (SD \$44) for adolescents. Using physician estimates for WTP as the reference group, adolescents were willing to pay $\$ 56$ more (95\% CI 48.6 to 63.4 ) for physician care and parents were willing to pay $\$ 66$ more (95\% CI 59.0 to 72.8 ) than physician's predicted controlling for informant employment status. Adolescents were willing to pay $\$ 36$ more (95\% CI 48.6 to 63.4 ) for community-based nursing care and parents were willing to pay $\$ 48$ more ( $95 \%$ CI 59.0 to 72.8 ) than physician's predicted. Consumers' (adolescents' \& parents') WTP for physician services were on average $\$ 18.50$ higher than PHN services $(\mathrm{p}=0.01)$.

Conclusion While adolescents and parents prefer physician followup for PID based on WTP, they are amenable to PHN follow-up visits. Our data suggest that health providers underestimate the value the consumers place on clinical service for PID. Given poor adherence to office-based follow-up and consumer interest in PHN visits, additional research evaluating the effectiveness of PHN visits for PID is warranted.

\section{P5-S6.33 HIV/AIDS IMPACT MITIGATION IN RESOURCE-POOR SETTINGS: SCALING-UP A MULTI-SECTORAL RESPONSE}

doi:10.1136/sextrans-2011-050108.589

${ }^{1}$ A Mwendwa, ${ }^{2} \mathrm{~N}$ Kyalo, ${ }^{3}$ W Kihara, ${ }^{4} \mathrm{~J}$ Mburu, ${ }^{5} \mathrm{M}$ Mutua. ${ }^{1}$ Moi University Hospital Teaching and Referral Centre, Eldoret, Kenya; ${ }^{2}$ University of Nairobi, Nairobi, Kenya; ${ }^{3}$ Kenyatta National Hospital, Nairobi, Kenya; ${ }^{4}$ Redeemed Gospel Church Development Programme, Nairobi, Kenya; ${ }^{5}$ Centre for Integrated Community Development and Outreach, CICDOT, Nairobi, Kenya

Background/issues The HIV and AIDS epidemic constitutes not only the worst scourge and onslaught with which peoples in resourcelimited places must contend; It also occurs in a context in which the effects of the epidemic and key issues which they engender are juxtaposed with a multiplicity of societal problems. Many high HIV/AIDS prevalence countries apparently remain unconvinced of the longer term impact of this epidemic, and have not yet developed strategies to cope with the obvious and incontrovertible impact of HIV and AIDS. Impact mitigation of HIV and AIDS is not high on the agenda of the many organisations which are involved in mounting a response to this epidemic. These organisations have assumed HIV/AIDS to be a public health issue and failed in many cases to recognise it for the socio-economic development challenge it more properly represents. Empirical research findings and Observations/In resource poor settings, greed and avarice of the political leadership overwhelms their responsibilities take urgent action to mitigate HIV/AIDS impact. There are small islands of dazzling abundance which exist side by side with a cheerless ocean of absolute poverty, dehumanising HIV/AIDS high prevalence rate and wide-scale social exclusion. Africa's famed traditional extended family system, exemplary at absorbing members under stress, is confronted with HIV and AIDS impact on every constituent part of its network and may reach breaking point without some assistance. This strain may have the effect of not only accelerating the reversal of development gains of the last decade but of fragmenting the very societal structure that has so far sustained marginal societies.

Conclusions/policy implications There's the pressing moral, social, political and economic imperative to scale up the impact mitigation of HIV/AIDS among residents of poor areas. The immediate focus of managing the crisis of HIV and AIDS in resource-limited settings will impact every aspect of multi-sectoral, systemic functioning, response. The advent of a vastly improved prognosis of new classes of ARV drugs and their use in combination can dramatically improve rates of mortality and morbidity, prolonged lives, improved quality of life, revitalised communities and transformed perceptions of HIV/AIDS from a plague to a manageable, chronic illness in resource poor settings.

\section{P5-S6.34 PROVIDER CHARACTERISTICS ASSOCIATED WITH GONORRHOEA TREATMENT ERRORS, MASSACHUSETTS, 2010}

doi:10.1136/sextrans-2011-050108.590

${ }^{1} \mathrm{~J}$ Swails, ${ }^{2} \mathrm{~L}$ Smock, ${ }^{2} \mathrm{Y}$ Tang, ${ }^{2} \mathrm{~K}$ Hsu. ${ }^{1}$ Brigham and Women's Hospital, Boston, USA; ${ }^{2}$ Massachusetts Department of Public Health USA

Background Massachusetts experienced a $29 \%$ increase in gonorrhoea cases during 2010. In $4 \%$ of cases where treatment was known, treatment was inconsistent with public health guidelines. We examined healthcare provider characteristics associated with gonorrhoea treatment errors to help target future educational outreach strategies. 